\title{
Evaluation of Gas Composition Obtained from Gasification of Pellets and Blends with Agricultural Wastes
}

\author{
Tuanne Gomes Porto ${ }^{\mathrm{a}}$, Walfran Tavares Oliveira ${ }^{\mathrm{a}}$, Fernanda Lopes ${ }^{\mathrm{a}}$, Danielle Venâncio ${ }^{\mathrm{a}}$, Gabriel Henrique \\ Wienhage $^{\mathrm{a}}$, Luana Marcele Chiarello ${ }^{\mathrm{a}}$ and Vinicyus Rodolfo Wiggers ${ }^{\mathrm{a}}$ \\ ${ }^{a}$ Department of Chemical Engineering, University of Blumenau, Blumenau, SC, Brazil
}

ARTICLE INFO

\section{Keywords:}

agricultural wastes,

downdraft gasifier,

waste-to-energy.
Co-gasification,

\begin{abstract}
The gas produced by gasification is more versatile than the original solid biomass and can be applied as raw material for chemical industry and as fuel for the electrical and thermal energy production. Small gasification plants are being considered as an option for electrical energy generation in remote areas where agriculture wastes can be found easily. In this way, the aim of this work was to evaluate the characteristics of the gas composition of co-gasification using pine pellets and blends with agricultural wastes. The experiments were carried out in duplicate in a pilot scale fixed bed downdraft gasifier, GEK Power Pallet $20 \mathrm{~kW}$. It was performed experimental runs with $100 \%$ pine pellets, $80 \%$ pine pellets and $20 \%$ agriculture wastes, and $80 \%$ pine pellets with $15.4 \%$ agriculture wastes and $4.6 \%$ of glycerol used as an agglutinant agent. The samples were analyzed by GC-FID/TCD. The moisture of different feedstocks varied between 8.00 and $10.88 \%$. The results of the produced gas show an average composition of $37.45 \% \mathrm{CO}$ and $15.79 \% \mathrm{H}_{2}$, and LHV $7,155 \mathrm{~kJ} / \mathrm{kg}$ for gasification of $100 \%$ pine pellets. While the mixture of pine pellets and agriculture wastes resulted in a gas with $32.13 \% \mathrm{CO}$ and $20.10 \% \mathrm{H}_{2}$, and LHV of $6,663.4 \mathrm{~kJ} / \mathrm{kg}$. When added glycerol, the gas composition to $\mathrm{CO}$ was $20.52 \%$ and to $\mathrm{H}_{2} 11.21 \%$ with LHV of $4,507.4 \mathrm{~kJ} / \mathrm{kg}$. The results indicate that the gasifier is compatible with the mixture of agricultural residues and pines pellets in co-gasification.
\end{abstract}

\section{Introduction}

The energy availability did not remain compatible with the increase in consumption unleashed by a new cycle of economic growth, observed especially in developing countries ${ }^{[1]}$. Thus, biomass for energy purposes can be considered the fuel with the greatest future potential as renewable energy, mainly due to the availability of agricultural, industrial and domestic waste. Waste-to-Energy technologies are widely cited as an alternative energy source that combines the proper disposal of waste. Among these technologies, thermal conversion process stands out: incineration, pyrolysis and gasification.

Gasification is one of the best technologies to convert biomass into fuels requiring high investment cost ${ }^{[2]}$. It is a thermochemical process where partial oxidation of biomass occurs at a high temperature (500-1800 ㄷ), under the action of a gasifying agent, such as air, oxygen, steam, carbon dioxide or a mixture of these, to produce a fuel gas ${ }^{[3]}$. The organic content of the biomass or organic wastes are converted mainly to carbon monoxide, hydrogen and lower amounts of methane. Although, the syngas is generally contaminated by undesired products such as particulate, tar, alkali metals, chloride and sulphide ${ }^{[4]}$. The gas produced makes the use more versatile, when compared to the use of the original solid biomass, and can be applied as raw material for the chemical industry ${ }^{[5]}$, as a fuel for electrical energy generation ${ }^{[6]}$ and for thermal energy production ${ }^{[7]}$. The downdraft gasifier is a type of fixed bed reactor generally used for small-scale heating and power applications ${ }^{[8]}$. In addition to having a simple configuration, this type of gasifier can produce fuel gas with better quality, mainly based on the tar content ${ }^{[9]}$.

The kinetics of gasification process occurs in four characteristic zones: drying, pyrolysis, combustion and reduction. These zones involve five stages that occur simultaneously: 1) stage of pyrolysis or thermal decomposition; 2) oxidation of part of the fixed carbon of the fuel; 3 ) gasification itself; 4) tar cracking and 5) partial oxidation of pyrolysis products.

Ramos et al. ${ }^{[10]}$ emphasize that the use of biomass blended with wastes is advantageous to increase energy generation and has awake the interest of several authors for the characteristics of the gas produced. Ahmed et al. ${ }^{[5]}$ investigated the evolution of the characteristics of the gas produced from raw materials composed of polyethylene and wood shavings in different proportions. It was observed that with the increase of polyethylene content in the mixture, the yields of hydrogen, ethylene and hydrocarbons in the composition of the gas produced also increased.

Peng et al. ${ }^{[11]}$ evaluated the co-gasification of forest residues and wet sewage sludge, using a fixed bed gasifier on a laboratory scale, with an operating temperature range of 700 to $900 \stackrel{\circ}{\circ}$, varying the mixture between both residues. It was observed that thermal decomposition was more efficient when adding forest biomass. The greatest efficiency of carbon conversion together with better yield was at $900{ }^{\circ} \mathrm{C}$, with the best mixture being $30 \%$ wet sewage sludge and $70 \%$ forest residues.

Ong et al. ${ }^{[12]}$ studied the co-gasification of wood chips and sewage sludge with up to $30 \%$ humidity in a fixed bed gasifier and downward flow, in order to determine the best condition of operation. The authors concluded that $20 \%$ of sewage sludge and $80 \%$ of wood chips in the mixture was effectively gasified, producing a gas with $30 \%$ by volume of synthesis gas with an average heating value of $4.5 \mathrm{MJ} / \mathrm{Nm}^{3}$. However, when the percentage of the sewage in the mixture increased to $33 \%$, the gasifier was blocked by the formation of ash agglomerate. 
In this way, the aim of this work was to evaluate the characteristics of the gas composition of co-gasification using pine pellets and blends with agricultural wastes in a downdraft gasifier.

\section{Methodology}

Pine pellets were purchased from a local manufacture of wood pellets. The agricultural residues used in this work came from cooperatives in the western of Santa Catarina (Brazil). Crude agricultural wastes were composed of residues from the soybean harvest (husks, whole, broken grains and straw). This residue was pre-treated through the pelletizing stage. All pellets had a relative homogeneity in size, $6 \mathrm{~mm}$ diameter and 10-45 mm length. The glycerin used was a by-product of biodiesel production and was used as a binding agent for the formation of pellets. To produce agricultural residue pellets with glycerin, the agricultural residue was mixed with glycerin until it was partially homogeneous and then the mixture was pelleted under the same conditions described before.

\subsection{Experimental Set-Up}

The experiments were carried out in duplicate in a pilot scale fixed bed downdraft gasifier, GEK Power Pallet 20 kW modificated (Figure 1), with $100 \%$ pine pellets (P100), $80 \%$ pine pellets and $20 \%$ agriculture wastes (P80W), and $80 \%$ pine pellets with $15.4 \%$ agriculture wastes and $4.6 \%$ of glycerol (P80WG). The gasifying conditions were similar for all feedstocks, between 510 and $568^{\circ} \mathrm{C}$ for the reduction temperature.

The pine pellets and the agricultural waste pellets at different concentrations were mixed and fed on the top of the unit's hopper, about $20 \mathrm{~kg}$ of each material for each run. The feedstock is fed through a screw to the gasifier until the sensor level indicates that it is completely full. After that, the feed mixture passes through the four zones in the gasifier: drying, pyrolysis, combustion and reduction. Air was used as an oxidizing agent and was introduced into the gasifier at the height of the combustion zone through a nozzle with a check valve. Below the combustion zone is the throat and the reduction zone and below that the grid responsible for removing the ashes that will not react anymore. The produced gas is then cooled, passing through the air intake compartment for heat exchange, going to the cyclone where the large solid particles present are removed and stored in the soot trap and then purified by the filter. The gas produced goes to the flare where it is burned. During the operation, two thermocouples were installed in the combustion and reduction zone, respectively, to measure the temperature inside the gasifier. A thermocouple and a pitot tube were installed at the outlet of the gas generated by the process in order to measure the temperature and the outflow of the gas, respectively.

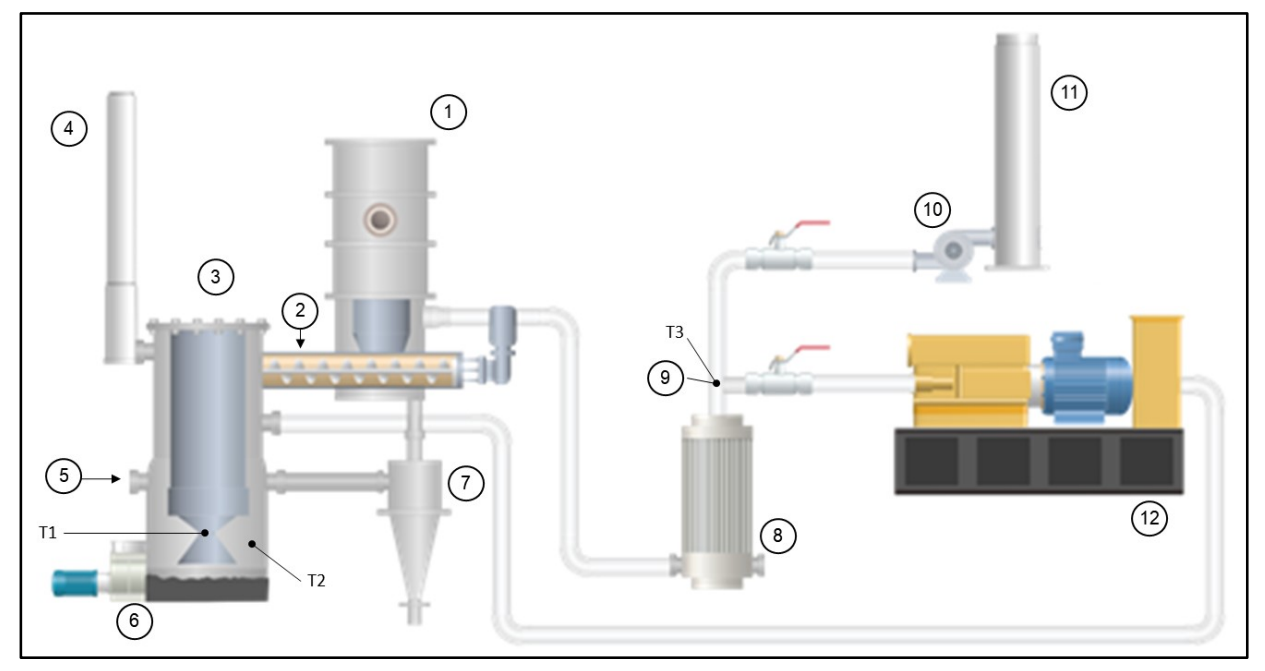

Figure 1. Schematic representation of pilot scale fixed bed downdraft gasifier: (1) Hopper, (2) Screw, (3) Gasifier, (4) Combustion gas exhaust, (5) Air inlet, (6) Automatic char removal, (7) Cyclone, (8) Gas filter, (9) Pitot tube, (10) Suction fan, (11) Flare, (12) Engine and Power Generation. T1 = temperature restrict reduction, $\mathrm{T} 2$ = temperature bottom reduction, and $\mathrm{T} 3$ = temperature reactor gas out.

Before the experiments, the feeding hopper (1), the gasifier (3), the char deposit (6) and the cyclone hooper (7) were empty and cleaned. After the experimental run, the cleaning procedure was repeated, and the remaining masses were collected and measured. The gasifier system was operated at atmospheric conditions about 2 hours for each experiment. The gas samples were collected in triplicate when the gasifier reached stability operation, approximately 30 minutes at same temperature, above filter exit, described as number 8 in Figure 1. The composition of the gas produced was immediately analyzed by chromatography analysis.

\subsection{Moisture, Thermogravimetric and Chromatography Analysis}

Proximate analysis was performed by thermogravimetric analysis (TGA) using DTG-60 (Shimadzu), according to standards ASTM E1131-08, and fixed carbon was calculated by difference. Moisture content in feedstock was also determined by automatic infrared (IR) moisture analyzer method, Ohaus NB25 according to NREL/TP-510-42621. Raw samples between 15 and $35 \mathrm{mg}$ were analyzed. The heating rate was $10 \circ \mathrm{C} / \mathrm{min}$,

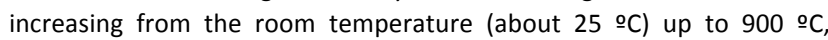
under argon gas flow at $100 \mathrm{~mL} / \mathrm{min}$. Gas samples from gasification experiments were analyzed by gas chromatography-flame ionization detection/thermal conductivity detection (GC-FID/TCD) as described by Beims et al. (2018) ${ }^{[13]}$ and quantified using an analytical curve. The high heating value (HHV) was determined according to the ASTM D240-19, while the lower heating value (LHV) was estimated in function of gas composition after GC-FID/TCD analysis.

\section{Results and Discussion}

Figure 2 shows the loss mass of pine pellets samples and agricultural wastes with temperature in TGA analysis. It was observed that all biomass samples analyzed presented similar thermal decomposition behaviour, however the wood residue (P100) indicated a faster loss of mass, when compared to the other biomass with agricultural residues in the absence or presence of glycerol. 


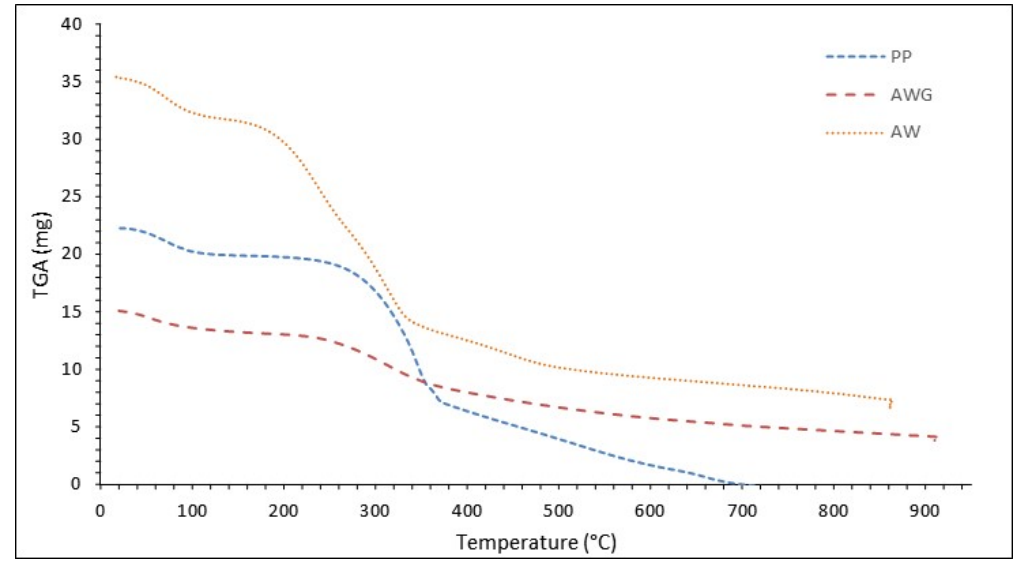

Figure 2. Thermogravimetric curves for different feedstock: pine pellets (PP), agricultural wastes (AW) and agricultural wastes with glycerol (AWG).

From the thermogravimetric analysis it was possible to determine the immediate analysis of the materials under study, as demonstrated in Table 1 . The moisture obtained from TGA analysis were very similar with 9.79, 10.54 and $9.46 \%$ for PP, AW and AWG, respectively. While the moisture from automatic IV moisture analyzer was 8.00, 8.73 and $10.88 \%$ for pine pellets (PP), agricultural wastes (AW), and agricultural wastes with glycerol (AWG), respectively. De Souza Araújo et al. ${ }^{[14]}$ compared moisture results from conventional oven and thermogravimetric analysis and concluded that the results were very similar and that TGA required less time for measurements, less sample consumption, simultaneous obtaining of moisture and ash content, in addition to allowing the visualization of its thermoanalytical profile.

Table 1. Moisture and proximate analysis from different feedstock before gasification.

\begin{tabular}{lccc}
\hline \hline Feedstock & Pine Pellts (PP) & Agricultural Wastes (AW) & Agricultural Wastes with Glycerol (AWG) \\
\hline Moisture IR analyzer (\%) & 8.00 & 8.73 & 10.88 \\
Moisture (\%) & 9.79 & 10.54 & 9.46 \\
Volatile content (\%) & 59.36 & 34.53 & 50.90 \\
Fixed carbon (\%) & 30.85 & 29.62 & 21.06 \\
Ash content (\%) & 0.00 & 25.31 & 18.54 \\
\hline \hline
\end{tabular}

The AW presented highest ash content around $25 \%$, when added glycerol (AWG) the value decreased to approximately $18 \%$. The $0 \%$ of ash content observed for PP was similar to the literature ${ }^{[15]}$, while the AW and AWG values corresponded to the values observed by Ong et al. ${ }^{[12]}$ investigated the co-gasification of wood chips and sewage sludge. The addition of glycerol to the agricultural wastes increased about to $16 \%$ the volatile content, when compared to the pure AW. High heating values of biomasses were $19,260.0 \mathrm{~kJ} / \mathrm{kg}, 12,242.8 \mathrm{~kJ} / \mathrm{kg}$ and $12,823.5 \mathrm{~kJ} / \mathrm{kg}$, respectively. The HHV values obtained were similar with Patel et al. ${ }^{[16]}$, that evaluate the co-gasification of lignite and waste wood.
The produced gas (Table 2) shows an average composition of $39.12 \%$ $\mathrm{CO}, 2.67 \% \mathrm{CH}_{4}, 9.92 \% \mathrm{CO}_{2}, 1.03 \% \mathrm{C}_{2} \mathrm{H}_{4}, 0.23 \% \mathrm{C}_{2} \mathrm{H}_{6}, 12.79 \% \mathrm{H}_{2}$ and $34.60 \% \mathrm{~N}_{2}$ for pine pellets only (P100). While the mixture of pine pellets and agriculture wastes (P8OW) resulted in $30.51 \% \mathrm{CO}, 2.54 \% \mathrm{CH}_{4}, 11.39$ $\% \mathrm{CO}_{2}, 0.83 \% \mathrm{C}_{2} \mathrm{H}_{4}, 0.13 \% \mathrm{C}_{2} \mathrm{H}_{6}, 17.61 \% \mathrm{H}_{2}$ and $37.53 \% \mathrm{~N}_{2}$. When $4.6 \%$ glycerol was used together with pine pellets and agricultural wastes (P80WG) the average composition was $20.94 \% \mathrm{CO}, 2.21 \% \mathrm{CH}_{4}, 10.05 \%$ $\mathrm{CO}_{2}, 0.89 \% \mathrm{C}_{2} \mathrm{H}_{4}, 0.25 \% \mathrm{C}_{2} \mathrm{H}_{6}, 10.35 \% \mathrm{H}_{2}$ and $55.47 \% \mathrm{~N}_{2}$. Lower heating value of produced gas is $6,814.0 \mathrm{~kJ} / \mathrm{kg}$ for $\mathrm{P} 100,6,393.3 \mathrm{~kJ} / \mathrm{kg}$ for $80 \%$ $\mathrm{P} 80 \mathrm{~W}$, and $4,323.4 \mathrm{~kJ} / \mathrm{kg}$ for P80WG. The average temperature to each

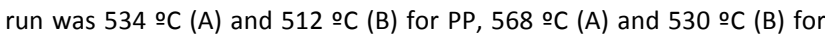
$\mathrm{P} 80 \mathrm{~W}$, and 512 ㅇ $\mathrm{C}(\mathrm{A})$ and 515 ㅇ $\mathrm{C}(\mathrm{B})$ for P80WG.

Table 2. Gas composition obtained after GC-FID/TCD analysis from gasification experiments.

\begin{tabular}{|c|c|c|c|c|c|c|c|c|c|}
\hline \multirow{2}{*}{ Feedstock } & \multirow{2}{*}{ Run } & \multicolumn{7}{|c|}{ Average composition ${ }^{ \pm \text {standard deviation }}(\%)$} & \multirow{2}{*}{ LHV $(\mathrm{kJ} / \mathrm{kg}$} \\
\hline & & $\mathrm{CO}$ & $\mathrm{CH}_{4}$ & $\mathrm{CO}_{2}$ & $\mathrm{C}_{2} \mathrm{H}_{4}$ & $\mathrm{C}_{2} \mathrm{H}_{6}$ & $\mathrm{H}_{2}$ & $\mathbf{N}_{2}$ & \\
\hline \multirow{2}{*}{ P100 } & A & $40.78^{ \pm 1.2}$ & $2.59^{ \pm 0.2}$ & $10.46^{ \pm 0.5}$ & $1.03^{ \pm 0.1}$ & $0.21^{ \pm 0.1}$ & $9.79^{ \pm 0.5}$ & $35.35^{ \pm 0.9}$ & $6,472.9^{ \pm 86.2}$ \\
\hline & B & $37.45^{ \pm 1.1}$ & $2.75^{ \pm 0.2}$ & $9.38^{ \pm 0.5}$ & $1.02^{ \pm 0.1}$ & $0.24^{ \pm 0.1}$ & $15.79^{ \pm 0.6}$ & $33.85^{ \pm 0.6}$ & $7,155.0^{ \pm 19.4}$ \\
\hline \multirow{2}{*}{ P80W } & A & $28.88^{ \pm 0.3}$ & $2.77^{ \pm 0.3}$ & $11.09^{ \pm 0.5}$ & $0.96^{ \pm 0.1}$ & $0.26^{ \pm 0.0}$ & $15.11^{ \pm 0.3}$ & $41.18^{ \pm 1.5}$ & $6,123.1^{ \pm 236.5}$ \\
\hline & B & $32.13^{ \pm 1.3}$ & $2.30^{ \pm 0.2}$ & $11.69^{ \pm 0.2}$ & $0.70^{ \pm 0.0}$ & $0.00^{ \pm 0.0}$ & $20.10^{ \pm 1.0}$ & $33.87^{ \pm 1.6}$ & $6,663.4^{ \pm 242.5}$ \\
\hline \multirow{2}{*}{ P80WG } & A & $20.52^{ \pm 1.7}$ & $1.90^{ \pm 0.2}$ & $8.34^{ \pm 0.4}$ & $0.80^{ \pm 0.1}$ & $0.22^{ \pm 0.0}$ & $11.21^{ \pm 0.9}$ & $56.64^{ \pm 3.1}$ & $4,507.4^{ \pm 331.2}$ \\
\hline & B & $21.36^{ \pm 2.6}$ & $2.51^{ \pm 0.2}$ & $11.75^{ \pm 1.2}$ & $0.98^{ \pm 0.1}$ & $0.27^{ \pm 0.0}$ & $9.48^{ \pm 1.4}$ & $54.29^{ \pm 3.8}$ & $4,139.4^{ \pm 541.6}$ \\
\hline
\end{tabular}

$\mathrm{O}_{2}$ was not detected in any of the gasification experiments and the $\mathrm{N}_{2}$ content was calculated by the difference from all other gases. As observed in Table 2, the $\mathrm{CO}$ content decreased significantly with the cogasification with glycerol, $46.5 \%$ from P100 to P80WG, followed by $\mathrm{CH}_{4}$ and $\mathrm{C}_{2} \mathrm{H}_{4}$ with $17.2 \%$ and $13.6 \%$, respectively. $\mathrm{CO}_{2}$ and $\mathrm{H}_{2}$ showed fluctuations in concentration, with the highest value for P80W sample. The content of $\mathrm{N}_{2}$ increased significatively for P80WG and consequently, the LHV decreased. Therefore, the glycerol addition did not represent a positive influence on the reactions.

As presented in Table 3, the mass balance did not present significative changes when the feed rate of feedstock was changed. Previous studies have reported the same feed range used, wood pellets and sewage sludge ${ }^{[12]}$ and wood and SRF ${ }^{[17]}$. The runs presented between 1.10 and $1.95 \mathrm{~kg} / \mathrm{h}$ of char and ash formed at the bottom of the gasifier. 
Table 3. Mass balance from gasification and co-gasification experiments.

\begin{tabular}{cccc}
\hline \hline Feedstock & Run & Feed rate $(\mathbf{k g} / \mathbf{h})$ & Char + Ash production rate $(\mathbf{k g} / \mathbf{h})$ \\
\hline \multirow{2}{*}{ P100 } & A & 11.25 & 1.95 \\
& B & 11.50 & 1.39 \\
P80W & A & 10.82 & 1.17 \\
& B & 9.32 & 1.44 \\
P80WG & A & 10.80 & 1.10 \\
& B & 10.65 & 1.44 \\
\hline \hline
\end{tabular}

\section{Conclusions}

The gasifier operation with the sample P100, P80W and P80WG proved to be stable in all experimental runs, without significant temperature fluctuations. The aim of applying co-gasification in this work was to use agricultural wastes to produce a gas with high LHV value. When applying $20 \%$ of residue in gasification (P8OW) the decreased of average LHV value was only $6.2 \%$ when compared to $100 \%$ pine pellet (P100). Biomass gasification and co-gasification produced a gas stream called syngas. The maximum hydrogen content was $17.61 \%$ for P80W, indicating that the glycerol addition did not contribute significantly. The results indicate that the gasifier is compatible with the mixture of agricultural residues and pines pellets in co-gasification.

\section{Acknowledgements}

The authors are grateful to the reviewers, to the Universidade de Blumenau (FURB) and Estado de Santa Catarina/UNIEDU, to the Conselho Nacional de Desenvolvimento Científico e Tecnológico (CNPq, no. 304560/2020-0), PIBITI/CNPq/FURB and to Fundação de Amparo à Pesquisa e Inovação do Estado de Santa Catarina (FAPESC, 2018/TR1537) for the financial support that made this article possible. This study was financed in part by the Coordenação de Aperfeiçoamento de Pessoal de Nível Superior - Brasil (CAPES) - Finance Code 001.

\section{Declaration of Interest}

The authors declare that they have no known competing financial interests or personal relationships that could have appeared to influence the work reported in this paper.

\section{References}

[1] ANEEL - Agência Nacional de Energia Elétrica. (2008). Parte III Fontes não-renováveis: derivados de petróleo.

[2] Guedes, R. E.; Luna, A. S.; Torres, A. R. (2018). Operating parameters for bio-oil production in biomass pyrolysis: A review. J. Anal. Appl. Pyrolysis, pages 134 - 149.

[3] Zhang, W.; Huang, S.; Wu, S.; Wu, Y.; Gao, J. (2019). Study on the structure characteristics and gasification activity of residual carbon in biomass ashes obtained from different gasification technologies. Fuel, pages 115699.

[4] Adnan, M. A.; Susanto, H.; Binous, H.; Muraza, O.; Hossain, M. M. (2017). Feed compositions and gasification potential of several biomasses including a microalgae: A thermodynamic modeling approach. Int. J. Hydrogen Energy, pages 17009 - 17019.

[5] Ahmed, I. I.; Nipattummakul, N.; Gupta, A. K. (2011). Characteristics of syngas from co-gasification of polyethylene and woodchips. Appl. Energy, pages 165 - 174.
[6] Yoon, S. J.; Son, Y. I.; Kim, Y. K.; Lee, J. G. (2012). Gasification and power generation characteristics of rice husk and rice husk pellet using a downdraft fixed-bed gasifier. Renew. Energy, pages 163 167.

[7] Sheth, P. N.; Babu, B. V. (2009). Experimental studies on producer gas generation from wood waste in a downdraft biomass gasifier. Bioresour. Technol., pages 3127 - 3133.

[8] Bhoi, P. R.; Huhnke, R. L.; Kumar, A.; Indrawan, N.; Thapa, S. (2018). Co-gasification of municipal solid waste and biomass in a commercial scale downdraft gasifier. Energy, pages 513 - 518.

[9] Susastriawan, A. A. P.; Saptoadi, H.; Purnomo, Y. (2019). Comparison of the gasification performance in the downdraft fixed-bed gasifier fed by different feedstocks: Rice husk, sawdust, and their mixture. Sustain. Energy Technol. Assessments, pages 27 - 34.

[10] Ramos, A.; Monteiro, E.; Silva, V.; Rouboa, A. (2018). Co-gasification and recent developments on waste-to-energy conversion: A review. Renew Sustain Energy Rev, pages 380 - 398.

[11] Peng, L.; Wang, Y.; Lei, Z.; Cheng, G. (2012). Co-gasification of wet sewage sludge and forestry waste in situ steam agent. Bioresour. Technol., pages $698-702$.

[12] Ong, Z.; Cheng, Y.; Maneerung, T.; Yao, Z.; Tong, Y. W.; Wang, C. H.; Dai, Y. (2015). Co-gasification of woody biomass and sewage sludge in a fixed-bed downdraft gasifier. AIChE J., pages 2508 - 2521.

[13] Beims, R. F.; Botton, V.; Ender, L.; Scharf, D. R.; Simionatto, E. L.; Meier, H. F.; Wiggers, V. R. (2018). Effect of degree of triglyceride unsaturation on aromatics content in bio-oil. Fuel, pages 175 - 184.

[14] De Souza Araújo, A. A.; Mercuri, L. P.; Stuckert Seixas, S. R.; Storpirtis, S.; Do Rosário Matos, J. (2006). Determinação dos teores de umidade e cinzas de amostras comerciais de guaraná utilizando métodos convencionais e análise térmica. Rev. Bras. Ciencias Farm. J. Pharm. Sci., pages 269 - 277.

[15] Salem, A. M.; Nuran, I.; Paul, M. C.; Yang, W. (2019). The evolution and formation of tar species in a downdraft gasi fi er: Numerical modelling and experimental validation. Biomass and Bioenergy, pages 105377.

[16] Patel, V. R.; Patel, D.; Varia, N.; Patel, R. N. (2017). Co-gasification of lignite and waste wood in a pilot-scale $(10 \mathrm{kWe})$ downdraft gasifier. Energy, pages 834 - 844.

[17] Vonk, G.; Piriou, B.; Dos, P. F.; Wolbert, D.; Vaïtilingom, G. (2019) Comparative analysis of wood and solid recovered fuels gasification in a downdraft fixed bed reactor. Waste Manag., pages 106 - 120. 